\title{
Dysregulation of Non-Heme Iron Metabolism in Glial Brain Tumors
}

\author{
Olga Mykhaylyk ${ }^{a}$ Nataly Dudchenko ${ }^{a}$ Ada Cherchenko ${ }^{b}$ \\ Volodymir Rozumenko ${ }^{b}$ Yuriy Zozulya ${ }^{b}$ \\ ${ }^{a}$ Institute for Applied Problems in Physics and Biophysics, NAS of the Ukraine, and \\ ${ }^{b}$ A.P. Romodanov Institute of Neurosurgery, AMS of the Ukraine, Kyiv, Ukraine
}

\section{Key Words}

Glial brain tumors · Patients - Experimental models in rats · Transferrin iron - Chelatable iron · Stored iron • Electron spin resonance

\begin{abstract}
Objective: To study iron exchange irregularities in experimental animals and patients with glial brain tumors to ascertain the role of the 'iron component' in glial brain tumor pathogenesis. Subject and Methods: A suspension of A.101.08 tumor cells was implanted in the cortex of the left-brain hemisphere of rats to model experimentally induced glial brain tumor. At 7 or 14 days after implantation, blood and tissue samples from the tumor, peritumoral tissue, and brain regions were taken for analysis. Blood and plasma samples were obtained from 23 patients as well as biopsy samples taken during tumor removal surgery. Electron resonance spectroscopy was used to determine the concentrations of transferrin iron, transferrin in whole blood and in blood cells, and chelatable and stored iron in the tissues of experimental animals and patients. Results: Hypoferremia was found in rats with both small and large glial brain tumors, whereas hyperferremia was found to be a characteristic of malignant glial brain tumors in humans. We identified statistically significant increases in stored and chelatable
\end{abstract}

iron concentrations in the tumor and peritumoral brain tissue compared to the blood and the adjacent brain tissue (probably normal) in both human malignant glial brain tumors and in rat experimental glial brain tumors. Conclusions: These findings suggest that iron misregulation plays a part in glial brain tumor pathogenesis and this may provide a basis for understanding the association between glial brain tumors and epilepsy.

Copyright (c) 2005 S. Karger AG, Basel

\section{Introduction}

Epidemiological studies point to the association of iron overload with liver carcinoma, colorectal and ovarian cancers [1-3]. Individuals who are homo- or heterozygous for hereditary hemochromatosis also have an increased risk of developing neoplastic diseases [4]. Iron overload has been shown to be a risk factor for cancer development in animal models whereas iron depletion prevents the growth of cancer cells in vitro [5]. Iron 'withholding', resulting in hypoferremia, is considered to be a defense against neoplasia [6], and hypoferremia is characteristic of carcinoma, melanoma, sarcoma and cancers of the hematopoietic tissues in humans [7]. Increased concentrations of low-molecular weight iron (LMWI) complexes are considered to contribute significantly to

\section{KARGER}

Fax +4161306 1234

E-Mail karger@karger.ch

www.karger.com
(C) 2005 S. Karger AG, Basel

$1011-7571 / 05 / 0144-0221 \$ 22.00 / 0$

Accessible online at:

www.karger.com/mpp
Dr. Olga Mykhaylyk

Institut für experimentelle Onkologie und Therapieforschung

Ismaningerstrasse 22

DE-81675 München (Germany)

Tel. +49 1609512 1846, Fax +49 894140 4476, E-Mail Olga.Mykhaylyk@gmx.net 
tissue damage through such mechanisms as free radical reaction catalysis, DNA injury, a shift to cell proliferation rather than apoptosis, and inhibition of mitochondrial electron transport [8-10]. Brain tissues are especially susceptible to oxidative damage due to the high content of unsaturated fatty acids and relatively low activity of the antioxidant system compared to other tissues [11].

Tumor cells, including brain tumor cells and especially glioblastomas, are characterized by increased transferrin receptor expression compared to normal brain tissues, both in vitro and in vivo [9]. While ferritin synthesis is activated in some cancer cells [12], much less is known about the shifts in non-heme iron exchange in brain tumor growth. Hence we decided to investigate non-heme iron exchange in experimental rat glial brain tumors and in biopsied human glial brain tumors using an electron spin resonance (ESR) technique to determine if the nonheme iron composition of the blood and brain regions were linked to brain tumor pathogenesis.

\section{Subjects and Methods}

\section{Experimental Rat Model of Glial Brain Tumor Formation}

The animal research was approved by the Ethics Committee, Romodanov Institute of Neurosurgery, Academy of Medical Sciences, Ukraine (AMSU). A suspension of A.101.08 tumor cells (atypical astrocytoma, close to glioblastoma) was implanted into the cortex of the left-brain hemisphere of male rats aged 7-8 days $(\mathrm{n}=14)$. At 7 or 14 days following implantation, samples of whole heparinized blood and liver tissue as well as samples of the brain tissue from the tumor (perifocal zone, cortex zones, the right hemisphere cortex, and hypothalamus) were removed for analysis. Samples of whole heparinized blood, liver, cortex and hypothalamus were also taken from the control animals (males, aged 18-20 days, $\mathrm{n}=5$ ). Animals with glial brain tumors were divided into two groups according to the size of the tumor: group 1 rats with a tumor diameter less than $3 \mathrm{~mm}$ (small tumors, $\mathrm{n}=8$ ) and group 2 rats with a tumor diameter greater than $8 \mathrm{~mm}$ (large tumors, $\mathrm{n}=6$ ).

\section{Patients}

The study protocol was also approved by the Ethics Committee, Romodanov Institute of Neurosurgery, AMSU. A total of 40 subjects were studied: 23 patients with glial brain tumors (17 men and 6 women, mean age $39.5 \pm 3.5$ years) and 17 control subjects ( 8 men and 9 women, mean age $42.6 \pm 2.1$ ) without tumors. Of the 23 patients 11 had grade III-IV anaplastic astrocytoma, 3 grade III oligodendroastrocytoma, 2 grade III-IV ependymoastrocytoma, 1 protoplasmic astrocytoma, 1 fibrillar astrocytoma, and 5 glioblastoma. In the morning on the day before surgery, venous blood samples were collected in heparinized tubes from overnight fasted patients and control subjects. Plasma was recovered by centrifugation of the heparinized blood at $1,300 \mathrm{~g}$ for $10 \mathrm{~min}$. The packed cell volume, or hematocrit $(\mathrm{Ht})$, was determined by centrifuging the blood specimen in capillary tubes and measuring the relative height of the red blood cell column. Biopsy samples were taken from three brain regions after radical removal of the tumor: the tumor zone, the perifocal zone adjacent to the tumor (peritumoral zone I), and the perifocal zone distant from the tumor (peritumoral zone II).

\section{Chemicals and Solutions}

Human apo-transferrin (product No. T2252), HEPES sodium salt (H7006), deferoxamine (D9533), iron (III) citrate (F61290), tris(hydroxymethyl)aminomethane (T1503), ammonium iron (III) sulfate (F1018), thioglycolic acid sodium salt (T0632), and 1,10phenanthroline monohydrate (P9375) were purchased from SigmaAldrich (St. Louis, Mo., USA).

All chemical operations were carried out using double distilled deionized water. To remove all traces of metals, glassware was washed with $1 \% \mathrm{NaOH}$ and $2 \%$ EDTA aqueous solution. To prepare transferrin iron calibration samples, aliquots of $25 \mu \mathrm{l}$ iron (III) citrate in the range of $0.7-7 \mathrm{~m} M$ concentration were incubated with $150 \mu 1$ of $0.24 \mathrm{~m} M$ apo-transferrin in $1 M$ HEPES buffer, $\mathrm{pH}=7.4$, in the presence of excess carbonate (final concentration $20 \mathrm{mM}$ ) for $24 \mathrm{~h}$ at $4^{\circ} \mathrm{C}$. These were then frozen in liquid nitrogen and stored until used.

To prepare iron (III)-Df calibration samples, $25 \mu \mathrm{l}$ of ammonium iron (III) sulfate solution with an iron concentration in the range of $1.5-15 \mathrm{~m} M$ was incubated with $100 \mu \mathrm{l}$ of $1.5 \mathrm{~m} M$ deferoxamine B solution in $0.5 \mathrm{M}$ Tris-HCI buffer, $\mathrm{pH}=7.0$, for $10 \mathrm{~min}$, frozen in liquid nitrogen and stored until used.

The iron concentration in the stock solutions was determined using a colorimetric method with 1,10-phenanthroline [13].

\section{Treatment of Tissue Samples}

Blood, plasma, and tissue samples for ESR analysis (8- to 100mg microsamples) were packed into cryoresistant, calibrated polymer ampoules and quickly frozen in liquid nitrogen $(77 \mathrm{~K})$, where they were stored until measured. Storage of the samples in liquid nitrogen did not have any discernable effect on the ESR spectra.

To determine the transferrin protein concentration, 75- to 100$\mu 1$ blood samples were treated with $20 \mu 1$ of $2.5 \mathrm{mM}$ Fe (III) citrate and $20 \mathrm{~m} M$ sodium bicarbonate in $0.1 \mathrm{M}$ HEPES, $\mathrm{pH} 7.4$, at $4{ }^{\circ} \mathrm{C}$ for $24 \mathrm{~h}$, frozen and stored until ESR measurements were made. To determine the amount of iron available for chelation, up to $100 \mathrm{mg}$ of blood or tissue samples were mixed with $25 \mu \mathrm{l}$ of $15 \mathrm{mM}$ Df solution in $0.5 \mathrm{M}$ Tris- $\mathrm{HCl}$ buffer, $\mathrm{pH} 7.0$, incubated for $30 \mathrm{~min}$ at $37^{\circ} \mathrm{C}$, frozen and stored until ESR measurements were made.

\section{ESR Spectra Registration and Calculations}

The ESR spectra were obtained using an EPA-10 mini spectrometer (St. Petersburg Instruments, Russia), at super high frequency of $9.30 \mathrm{GHz}$, on pressed cylindrical samples. The ESR spectra were recorded under nonsaturating conditions.

The transferrin iron concentration was determined using characteristic iron (III)-transferrin complex spectra at an effective g-factor of 4.3 (fig. 1, curve a) [14]. The chelatable iron concentrations in tissue and blood samples were determined based on the incorporation of LMWI into the iron-desferrioxamine B (Df) complexes with a characteristic ESR spectrum (fig. 1, curve b) upon treatment with Df solution $[15,16]$. The stored iron concentration in tissues was evaluated against the background of the wide magnetic resonance spectra in the g-factor range of 2.0-4.5 stipulated by ferritin and/or hemosiderin iron [17-19] (fig. 2). The relative methemoglobin $(\mathrm{MtHb})$ iron concentration was estimated using an amplitude 
Fig. 1. ESR spectra. Left panel: native iron (III)-transferrin complex $(\mathrm{g}=4.3)$ in human blood (a); temperature, $105 \mathrm{~K}$; modulation frequency, $100 \mathrm{kHz}$; modulation amplitude, 10 gauss; microwave frequency, 9.39 $\mathrm{GHz}$; power, $70 \mathrm{~mW}$. The same spectrum simulated as a sum of Lorentzian profile derivatives $\left(a^{\prime}\right)$. Right panel: iron (III)-desferrioxamine $\mathrm{B}$ complex in the human blood (b); temperature, $105 \mathrm{~K}$; modulation frequency, $100 \mathrm{kHz}$; modulation amplitude, 10 gauss; microwave frequency, $9.39 \mathrm{GHz}$; power, $50 \mathrm{~mW}$. The same spectrum simulated as a sum of Lorentzian profile derivatives $\left(b^{\prime}\right)$.

Fig. 2. ESR spectra of the stored (ferritin/ hemosiderin) iron, after sample freezing, in a spectrometer magnetic field of $250 \mathrm{Oe}\left(0^{\circ}\right)$ and sample rotation on a $90^{\circ}$ angle about the resonator axis. Tumor tissue from a patient with a glial brain tumor (a); tumor tissue (b) and blood (c) from rats with experimental glial brain tumors, and brainstem of a rat from the reference group (d). Conditions: temperature $145 \mathrm{~K}$; modulation frequency, $100 \mathrm{kHz}$; modulation amplitude, 10 gauss; microwave frequency, $9.39 \mathrm{GHz}$; power, $20 \mathrm{~mW}$.
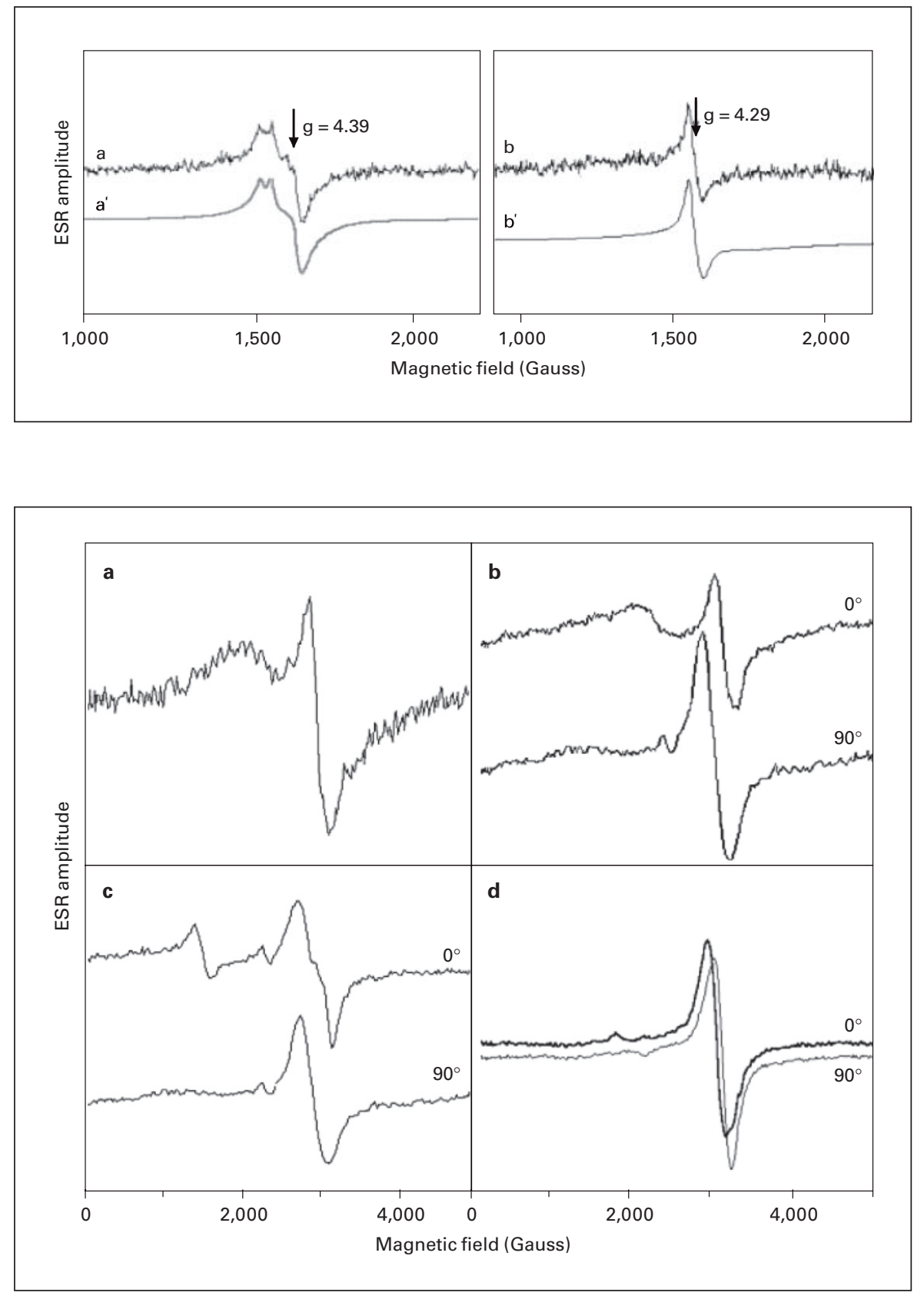

of the sharp ESR absorption derivative at $\mathrm{g}=6.0$, corresponding to the high-spin $\left(d^{5}\right) \mathrm{Fe}$ (III) configuration of the ferric iron in oxidized hemoglobin [20].

A CuEDTA sample of the same shape and size as above, prepared in a 1:1 water-glycerin matrix, was used as a reference sample. The $g$ value measurements were performed using the sextet of the $\mathrm{Mn}^{2+}$ in $\mathrm{MgO}$ matrix as a secondary standard. To improve the accuracy of the double integration, the ESR lines were simulated as a sum of Lorentzian profile derivatives after subtraction of the background signal, as shown in figure 1 , curves a' and $\mathrm{b}^{\prime}$. Calibration curves of the double integrated intensity versus iron concentration were obtained for each of the iron species. The tissue ferritin ESR spectra were calibrated against Mössbauer data [17].

The concentration of transferrin [Tf] in the blood or plasma was calculated as $[\mathrm{Tf}]=[\mathrm{Tf}-\mathrm{Fe}]_{\mathrm{sat}} / 2$, where $[\mathrm{Tf}-\mathrm{Fe}]_{\mathrm{sat}}$ was the transferrin iron content in a sample saturated with iron. Transferrin saturation with iron was calculated as $\% \mathrm{Tf}=100 \% \times[\mathrm{Tf}-\mathrm{Fe}] / 2[\mathrm{Tf}]$. The concentration of transferrin iron associated with blood cells $[\mathrm{Tf}-\mathrm{Fe}]_{\mathrm{bc}}$ 
Table 1. Indices of non-heme iron exchange, including transferrin iron concentration, [Tf-Fe], transferrin concentration, [Tf], transferrin saturation, \% $\mathrm{Tf}$, ferritin iron, $[\mathrm{Ft}-\mathrm{Fe}]$, and $\mathrm{MtHb}$ iron concentration, [MtHb-Fe], in patients with glial brain tumors (mean \pm SEM)

\begin{tabular}{lccl}
\hline Parameter & $\begin{array}{c}\text { Patients } \\
(\mathrm{n}=23)\end{array}$ & $\begin{array}{l}\text { Reference data } \\
(\mathrm{n}=17)\end{array}$ & $\mathrm{P}_{1}$ \\
\hline Whole blood & & & \\
Age, years & $42.6 \pm 2.1$ & $39.5 \pm 3.5$ & $\mathrm{NS}$ \\
& $(18-62)$ & $(29-74)$ & \\
$\mathrm{Hb}, \mathrm{g} / 1$ & $137.5 \pm 3.6$ & $137.6 \pm 3.4$ & $\mathrm{NS}$ \\
$\mathrm{Ht}$ & $0.46 \pm 0.01$ & $0.48 \pm 0.01$ & $\mathrm{NS}$ \\
{$[\mathrm{Tf}-\mathrm{Fe}], \mu \mathrm{M}$} & $18.3 \pm 0.8$ & $15.7 \pm 0.7$ & 0.984 \\
{$[\mathrm{Tf}], \mu \mathrm{M}$} & $31.7 \pm 2.4$ & $31.2 \pm 1.9$ & $\mathrm{NS}$ \\
\%Tf & $32.5 \pm 2.5$ & $27.2 \pm 1.7$ & $\mathrm{NS}$ \\
{$[\mathrm{MtHb}-\mathrm{Fe}]$, relative units } & $1.1 \pm 0.2$ & $3.1 \pm 1.0$ & 1.000 \\
{$[\mathrm{Ft}-\mathrm{Fe}], \mu \mathrm{M}$} & $44.3 \pm 10.6$ & $36.1 \pm 2.8$ & $\mathrm{NS}$ \\
\hline Blood cells & & & \\
$\quad[\mathrm{Tf}-\mathrm{Fe}], \mu \mathrm{M}$ & $9.0 \pm 1.0$ & $5.3 \pm 0.9$ & 0.988 \\
\hline Plasma $\quad$ & & \\
$\quad[\mathrm{Tf}-\mathrm{Fe}], \mu \mathrm{M}$ & $28.8 \pm 1.8$ & $25.8 \pm 1.1$ & $\mathrm{NS}$ \\
$\quad[\mathrm{Ft}-\mathrm{Fe}], \mu \mathrm{M}$ & $31.8 \pm 5.6$ & $26.3 \pm 5.7$ & $\mathrm{NS}$ \\
\hline
\end{tabular}

NS = Nonsignificant difference between data sets $\left(\mathrm{P}_{1}<0.95\right)$.

was calculated using the transferrin iron concentration in the blood $[\mathrm{Tf}-\mathrm{Fe}]_{\mathrm{bl}}$ and plasma $[\mathrm{Tf}-\mathrm{Fe}]_{\mathrm{pl}}$, and accounting for the $\mathrm{Ht}$ as follows:

$$
[\mathrm{Tf}-\mathrm{Fe}]_{\mathrm{bc}}=\frac{[\mathrm{Tf}-\mathrm{Fe}]_{\mathrm{bl}}-[\mathrm{Tf}-\mathrm{Fe}]_{\mathrm{pl}} \times(1-\mathrm{Ht})}{\mathrm{Ht}}
$$

\section{Statistical Analysis}

Data are represented as mean \pm SEM, where SEM is the standard error of the mean. To determine the difference between experimental and control data sets, the quantitative statistical measure, $\mathrm{P}_{1}$ (distance between data sets), was used: $\mathrm{P}_{1}=\Phi_{\mathrm{nm}}\left[\mathrm{T}_{1}(\mathrm{x}, \mathrm{y})\right]$, where $\Phi_{\mathrm{nm}}$ is the Snedecor-Fischer function:

$$
\mathrm{T}_{\mathrm{I}}(\xi, \eta)=\frac{\mathrm{n}+\mathrm{m}-\mathrm{I}-1}{\mathrm{I}} * \frac{\mathrm{nm}}{(\mathrm{n}+\mathrm{m})(\mathrm{n}+\mathrm{m}-2)} \mathrm{D}_{\mathrm{I}}^{2}(\xi, \eta)
$$

where $\mathrm{D}_{\mathrm{I}}^{2}(\zeta, \eta)$ is a Mehalanobis distance, and $\mathrm{I}$ is the number of parameters (factors). Parameters $n$ and $m$ were determined by the sample size for experimental and control data. The advantages of this estimation are the following: the $\mathrm{P}_{\mathrm{I}}$ value is a normalized one and varies in the range of $0-1$; the closer $P_{I}$ is to the unit, the less probable is the so-called 'zero' hypothesis on the absence of the effect. This estimation takes into account the interrelationships between factors and their coupled changes. In the partial case of $I=1$, $\mathrm{P}_{1}=\mathrm{S}_{\mathrm{nm}}\left(\mathrm{T}_{\mathrm{q}}(\mathrm{x}, \mathrm{y})\right)$, where $\mathrm{S}_{\mathrm{n}}(\mathrm{x})$, is the Student distribution function or $P_{1}=1-p$, where $p$ is a level of 'zero' hypothesis significance.

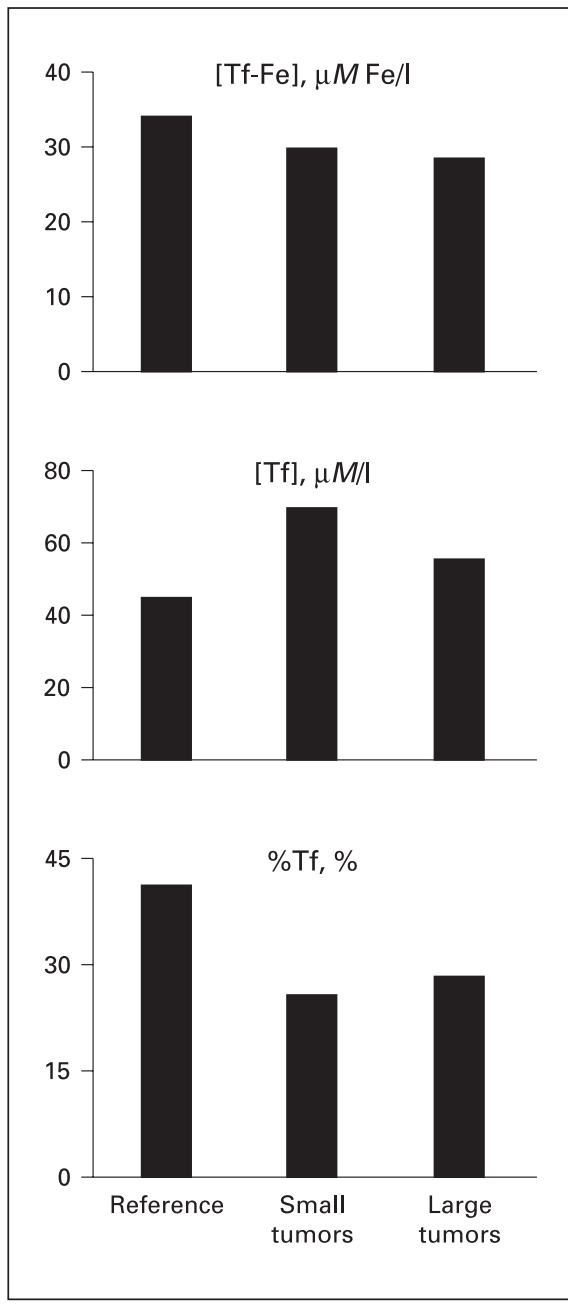

Fig. 3. Mean values of blood concentrations of transferrin iron, [Tf-Fe], transferrin, [Tf], and transferrin saturation, \% Tf, in groups of rats with small and large glial brain tumors.

\section{Results}

The average transferrin iron concentration in the blood of animals with small and large tumors (29.6 \pm 10.7 and $27.9 \pm 6.7 \mu M$, respectively) was less than in the control group $(33.8 \pm 5.8 \mu M)$, with $\mathrm{P}_{1}$ equal to 0.567 and 0.838 , respectively (fig. 3). Transferrin concentrations in the blood of rats with small $(68.8 \pm 29.7 \mu M)$ and large $(55.7 \pm 26.2 \mu M)$ tumors exceeded the control level $(43.9 \pm 14.3 \mu M), \mathrm{P}_{1}=0.888$ and 0.608 , respectively (fig. 3). Transferrin saturation in the blood was considerably lower than the control data $(40.9 \pm 13.7 \%)$, in animals with small $\left(25.1 \pm 13.7 \%, \mathrm{P}_{1}=0.932\right)$ and large 
Fig. 4. Mean values of ferritin/hemosiderin iron concentration, [Ft-Fe], and chelatable with desferrioxamine B iron concentrations, [Df-Fe], in tissues from the tumor zone in the left hemisphere, perifocal zone, cortex of the right brain hemisphere, hypothalamus, and liver in rats with small and large glial brain tumors compared to the reference data. Bright columns = reference data; dark columns $=$ small tumors; diagonal shaded columns $=$ large tumors. $* 0.9<\mathrm{P}_{1}<0.95$; $* * 0.95 \leq \mathrm{P}_{1}<0.99 ; * * * 0.99 \leq \mathrm{P}_{1}$.

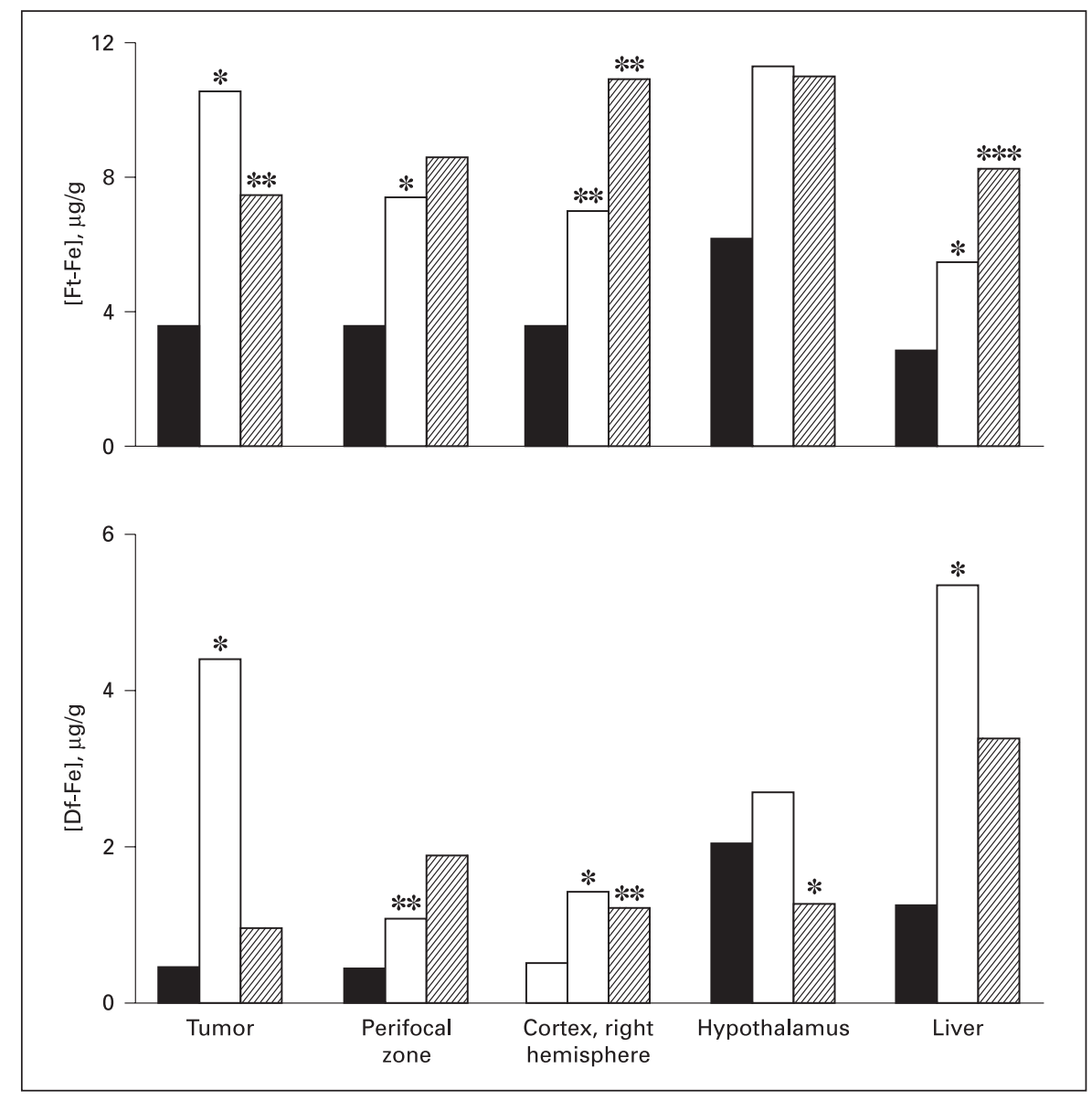

$\left(28.1 \pm 9.2 \%, \mathrm{P}_{1}=0.902\right)$ tumors, thereby indicating hypoferremia (fig. 3).

Ferritin iron concentrations in the blood and liver exceeded the control level for both small and large tumors (fig. 4) and were significantly higher $\left(P_{1}=0.99\right)$ in the livers of rats with large tumors. Stored iron content increased considerably (twofold to fourfold) compared to the control data in all brain tissues under study, in even the small tumors. The index was twofold higher than the reference value in the hypothalamus and the perifocal zone for both small and large tumors. In small tumors, a statistically significant correlation was observed between the stored iron concentration in the blood and the hypothalamus $(r=0.625 ; p=0.040)$ as well as between the stored iron concentration in the tumor, the peritumoral tissue, and the cortex of the right brain hemisphere $(p<0.05)$. For large tumors a correlation was observed between stored iron concentrations in the peritumoral tissue, the cortex of the right brain hemisphere, and the hypothalamus $(\mathrm{p}<0.002)$.
The chelatable iron concentration increased significantly in liver tissues and in all brain tissues except the hypothalamus (fig. 4). For small tumors, there was a statistically significant correlation $(r>0.99 ; p<0.001)$ between the chelatable iron concentration in the liver and all brain tissues studied. For large tumors, a significant correlation was observed between chelatable iron and stored iron concentration in the blood $(\mathrm{r}=0.744 ; \mathrm{p}=$ $0.021)$ and in all brain tissues: tumor tissue $(r=0.709$; $p=0.032)$, the peritumoral tissue $(r=0.780 ; p=0.013)$, the cortex of the right brain hemisphere $(r=0.712 ; p=$ $0.032)$, and the hypothalamus $(r=0.834 ; p=0.005)$. These correlations are indicative of the involvement of all brain tissues and the organism as a whole, in brain tumor development.

A combined statistical treatment of the differences between experimental and control data sets on non-heme iron exchange parameters is given in table 2 . With small brain tumors there were 19 combinations with a normalized distance between data sets, $\mathrm{P}_{\mathrm{I}}$ exceeding 0.98 , where- 
Table 2. Mehalanobis distance, $D_{I}$, and normalized distance, $P_{I}$, between experimental and control data sets for rats with small and large tumors as a result of the combined treatment of seven informative parameters of non-heme iron exchange: transferrin iron concentration, [Tf-Fe $]_{b l}$, transferrin saturation in the blood, $\% \mathrm{Tf}_{\mathrm{bl}}$, and stored iron concentration [Ft-Fe] in the tumor tissue (t), the cortex of the right brain hemisphere (c), the hypothalamus (hy) and the liver (lv)

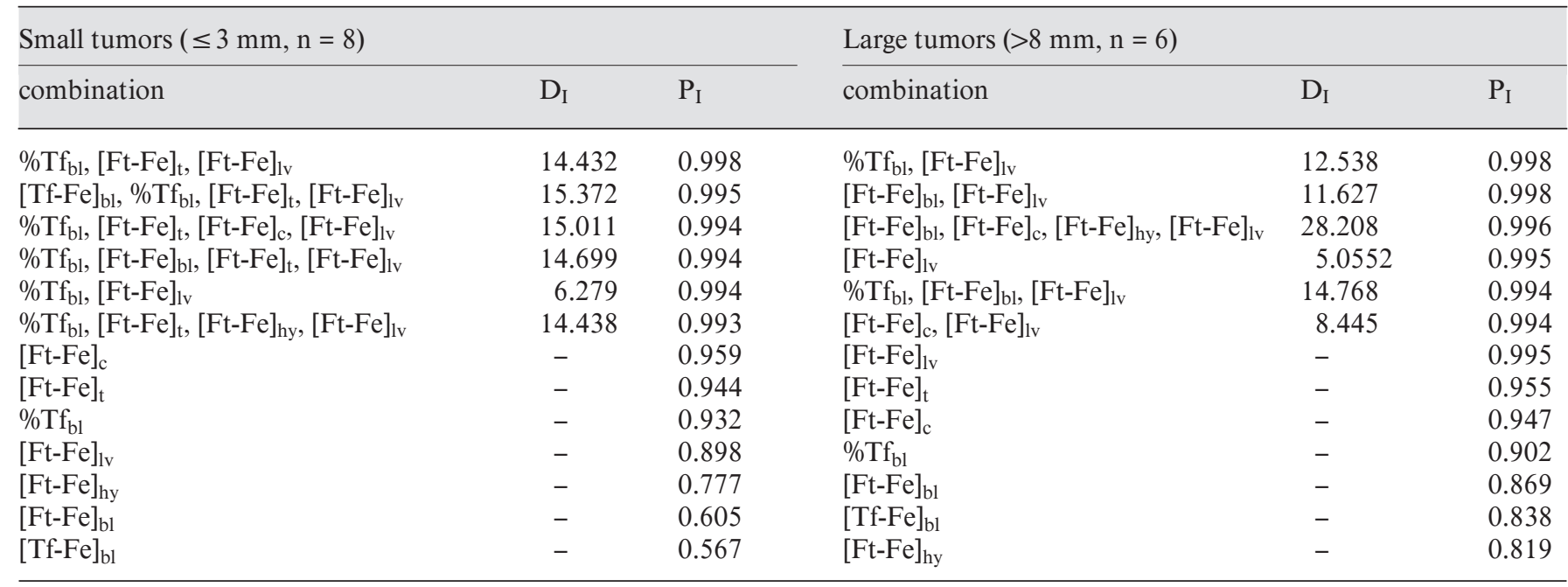

Only 6 combinations with $\mathrm{P}_{\mathrm{I}}>0.99$ in the order of $\mathrm{P}_{\mathrm{I}}$ decrease are represented from a total of $2^{7}$ possible combinations as well as the $\mathrm{P}_{\mathrm{I}}$ values upon separate treatment of every parameter (at the end of the table).

as with large brain tumors there were 23 . The high $\mathrm{P}_{\mathrm{I}}$ values (close to the unit) and an increase in the distance between samples upon combined parameter treatment indicate that the parameters were informative and the multifactorial approach was effective for estimating the distance between samples at glial brain tumors in rats. Normalized distance between samples as a function of the combination of non-heme iron exchange parameters could be introduced as an essential parameter in designing a risk model of glial brain tumors. In the case of animals with small tumors, combinations of indices with maximum distance between samples include transferrin saturation in the blood and the stored iron concentration in the liver and blood for both groups of animals, as well as the stored iron concentration in the tumor tissue and the cortex of the right brain hemisphere.

Non-heme iron exchange indices for the blood and biopsy samples taken from patients with glial brain tumors (table 1) show that the transferrin iron concentration values in the whole blood $(19.5 \pm 3.6 \mu M)$ were markedly and significantly higher $\left(\mathrm{P}_{\mathrm{I}}=0.997\right)$ than control data determined in healthy adults $(15.7 \pm 2.9 \mu M)$. The transferrin iron concentration in blood cells was also significantly $\left(\mathrm{P}_{\mathrm{I}}=0.982\right)$ higher in patients $(8.6 \pm 5.5 \mu M)$ than in healthy adults $(5.3 \pm 3.8 \mu M)$. The $\mathrm{MtHb}$ iron level in the blood of patients $(1.1 \pm 0.2$ relative units) was three-
Table 3. Concentration of ferritin iron $[\mathrm{Ft}-\mathrm{Fe}]$ and iron chelatable with deferoxamine B [Df-Fe] in the blood, glial tumor tissue, and peritumoral zones I and II of patients with glial brain tumors (mean $\pm \mathrm{SEM}$

\begin{tabular}{lllll}
\hline Parameter & Blood & $\begin{array}{l}\text { Tumor } \\
\text { tissue }\end{array}$ & $\begin{array}{l}\text { Peritumoral } \\
\text { zone I }\end{array}$ & $\begin{array}{l}\text { Peritumoral } \\
\text { zone II }\end{array}$ \\
\hline$[\mathrm{Ft}-\mathrm{Fe}], \mu \mathrm{mol} / 1$ & $44 \pm 10$ & $155 \pm 39$ & $203 \pm 55$ & $48 \pm 9$ \\
$\mathrm{P}_{1}$ & - & 0.9939 & 0.9997 & $\mathrm{NS}$ \\
{$[\mathrm{Df}-\mathrm{Fe}], \mu \mathrm{mol} / 1$} & $5.4 \pm 0.6$ & $17.8 \pm 2.9$ & $22.2 \pm 3.9$ & $6.5 \pm 0.1$ \\
$\mathrm{P}_{1}$ & - & 0.9994 & 1.000 & $\mathrm{NS}$ \\
\hline
\end{tabular}

NS = Nonsignificant difference between data sets $\left(\mathrm{P}_{1}<0.95\right)$.

fold lower than in the group of control subjects $(3.1 \pm 1.0$ relative units), and this difference was statistically significant $\left(\mathrm{P}_{\mathrm{I}}=1\right)$.

The ferritin iron indices increased considerably (threefold to fourfold) and significantly in the tumor tissue (135 $\pm 129 \mu M)$ and in peritumoral zone I $(209 \pm 160 \mu M)$ relative to peritumoral zone II, which was at a distance from the tumor. The ferritin iron indices also increased relative to the ferritin iron levels in patient blood and plasma (table 3), therefore, one can discriminate between normal and tumor tissue on the basis of ferritin iron con- 
Table 4. Mehalanobis distance $D_{I}$ and normalized distance $P_{I}$ between experimental and reference data sets as a result of combined treatment of seven informative parameters of non-heme iron exchange determined in patients with glial brain tumors and in healthy adults: transferrin iron concentration, $[\mathrm{Tf}-\mathrm{Fe}]_{\mathrm{bl}}$, transferrin concentration, $[\mathrm{Tf}]_{\mathrm{bl}}$, transferrin saturation in the blood, $\% \mathrm{Tf}_{\mathrm{bl}}$, stored iron concentration, [Ft-Fe], in tumor tissue (t), blood (bl) and plasma $(\mathrm{pl})$

\begin{tabular}{lll}
\hline Combination & $\begin{array}{l}\text { Mehalanobis } \\
\text { distance } \mathrm{D}_{\mathrm{I}}\end{array}$ & $\begin{array}{l}\text { Normalized } \\
\text { distance } \mathrm{P}_{\mathrm{I}}\end{array}$ \\
\hline$[\mathrm{Tf}]_{\mathrm{bl}},[\mathrm{Ft}-\mathrm{Fe}]_{\mathrm{t}}$ & 2.255 & 0.999 \\
{$[\mathrm{Tf}-\mathrm{Fe}]_{\mathrm{bl}},[\mathrm{Ft}-\mathrm{Fe}]_{\mathrm{t}}$} & 2.245 & 0.999 \\
{$[\mathrm{Tf}-\mathrm{Fe}]_{\mathrm{bl}},[\mathrm{Ft}-\mathrm{Fe}]_{\mathrm{pl}},[\mathrm{Ft}-\mathrm{Fe}]_{\mathrm{t}}$} & 2.784 & 0.999 \\
{$[\mathrm{Tf}]_{\mathrm{bl}}, \% \mathrm{Tf} \mathrm{bl}_{\mathrm{bl}},[\mathrm{Ft}-\mathrm{Fe}]_{\mathrm{t}}$} & 2.699 & 0.999 \\
{$[\mathrm{Tf}-\mathrm{Fe}]_{\mathrm{bl}},[\mathrm{Tf}]_{\mathrm{bl}},[\mathrm{Ft}-\mathrm{Fe}]_{\mathrm{t}}$} & 2.664 & 0.998 \\
{$[\mathrm{Tf}-\mathrm{Fe}]_{\mathrm{bl}},[\mathrm{Tf}-\mathrm{Fe}]_{\mathrm{pl}},[\mathrm{Ft}-\mathrm{Fe}]_{\mathrm{t}}$} & 2.618 & 0.998 \\
{$[\mathrm{Tf}-\mathrm{Fe}]_{\mathrm{pl}},[\mathrm{Tf}]_{\mathrm{bl}},[\mathrm{Ft}-\mathrm{Fe}]_{\mathrm{t}}$} & 2.605 & 0.998 \\
{$[\mathrm{Tf}-\mathrm{Fe}]_{\mathrm{bl}}, \% \mathrm{Tf} \mathrm{bl}_{\mathrm{bl}},[\mathrm{Ft}-\mathrm{Fe}]_{\mathrm{pl}},[\mathrm{Ft}-\mathrm{Fe}]_{\mathrm{t}}$} & 3.101 & 0.998 \\
{$[\mathrm{Tf}-\mathrm{Fe}]_{\mathrm{bl}}$} & - & 0.997 \\
{$[\mathrm{Ft}-\mathrm{Fe}]_{\mathrm{t}}$} & - & 0.996 \\
{$[\mathrm{Tf}-\mathrm{Fe}]_{\mathrm{pl}}$} & - & 0.855 \\
{$[\mathrm{Tf}]_{\mathrm{bl}}$} & - & 0.771 \\
{$[\mathrm{Ft}-\mathrm{Fe}]_{\mathrm{bl}}$} & - & 0.588 \\
$\%_{\mathrm{TTf}}^{\mathrm{bl}}$ & - & 0.683 \\
{$[\mathrm{Ft}-\mathrm{Fe}]_{\mathrm{pl}}$} & & 0.4945 \\
\hline
\end{tabular}

$[\mathrm{Ft}-\mathrm{Fe}]_{\mathrm{t}}$, ferritin iron concentration in the tumor tissue, was compared to ferritin iron concentration in the blood.

centration. The chelatable iron concentration increased significantly in the tumor tissue and in peritumoral zone I relative to peritumoral zone II, whole blood, and blood plasma. The differences we detected were statistically significant. The most informative parameter combinations ensuring the maximum normalized distance between data sets on non-heme iron exchange parameters in patients with glial brain tumors included the concentration of transferrin iron in the blood, transferrin saturation in the blood, and ferritin/hemosiderin iron concentration in the tumor tissue (table 4).

\section{Discussion}

Non-heme iron indices in patient groups and experimental animals are generally investigated using magnetic properties of non-heme iron species [14-19]. The phenomenon of ESR has its origin in splitting the energy levels of atomic species with nonzero electron magnetic moment in an outer, static magnetic field (electron Zeeman effect) [21]. In practice, the magnetic field is swept through the resonance while the frequency is kept constant, thus modulating the magnetic field to improve the signal-tonoise ratio. The ESR signal registered is the first derivative of an adsorption line.

Contrary to the common methods of non-heme iron status estimation, ESR method allows analysis of whole blood microsamples, achieving specificity in transferrin iron determination and allowing the determination of transferrin saturation in whole blood [14]. In addition, the new index - concentration of transferrin iron associated with blood cells - can be calculated from blood and plasma transferrin iron concentrations by taking into account the hematocrit index.

Our data show that hypoferremia was developed upon glial brain tumor formation in the rat model, whereas hyperferremia was detected in patients with spontaneous tumor formation. These findings indicate that increased stored and chelatable iron in the tumor tissue and the adjacent peritumoral tissues are features common to glial brain tumor formation in both experimental animals and in patients.

These abnormalities can occur at any stage of iron regulation including iron uptake, storage and release, utilization, and regulation. It has been shown that non-transferrin-mediated mechanisms are involved in iron influx into brain cells [22], mediated by DMT1 coupled with ferric reductase Dcytb expressed by astrocytes [23]. Actively dividing astrocytic and tumor astroglial cells exhibit considerably higher expression of the DMT1 than nonproliferating cells [24]. The resultant increase in LMWI level leads to oxidative stress exacerbation, activation of ferritin synthesis [25] and, hence, to iron sequestration. This correlates with the up-regulation of manganese superoxide dismutase in human glioblastomas [26]. The immunosuppressive effect of ferritin [27] can, in turn, promote tumor growth.

Two stress proteins, heme oxygenase-1 (HO-1) and NO synthase, could also contribute to the increase in the redox-active iron pool and iron deposition, as reported in the present work. Induction of HO-1 [28] results in increased bilirubin and available iron and ferritin levels. Induction of the glial HO-1 was shown to lead to iron sequestration in mitochondria and to mitochondrial insufficiency in human central nervous system disorders [29]. Both hypoxia and nitrogen monoxide can also induce ferritin synthesis [30].

Stored iron accumulation during glial brain neoplasm formation could explain the robust association between glioma and epilepsy [31], as epilepsy could be the initial 
and only clinical manifestation of a glioma [32, 33]. Iron deposition is a prominent feature of human post-traumatic epilepsy [34]. Subcranial injection of iron-containing products into the cortex was shown to produce a chronic epileptic focus in experimental models [35]. The efficacy of antioxidants in preventing iron-induced epileptiform activity in animal models suggests an important role for oxidative injury in the development of experimental epilepsy [36]. We have also found plausible shifts in iron status in animals using the Kindling epilepsy model. In particular, considerable increases in the ferritin iron level in hippocampal tissue were reliably established.

$\mathrm{MtHb}$ is thought to be a marker for oxidative stress. Surprisingly, in patients with glial brain tumors we found a statistically significant threefold decrease in MtHb levels in the blood compared to reference data. One could speculate that the decrease in steady-state $\mathrm{MtHb}$ iron concentration in the blood occurred due to the release of hemin, which, in turn, can contribute significantly to increased proliferation of cancerous cells, as was shown in vitro for human glioma cell lines [37]. Alternatively, adaptive activation of the NADH-methemoglobin reductase could account for the decreased $\mathrm{MtHb}$ in tumor patients [38].

We found that the most informative parameter combinations distinguishing between patients and control subjects included transferrin iron concentration in the blood, transferrin saturation in the blood, and ferritin/hemosiderin iron concentration in the tumor tissue.

Iron accumulation in tumor tissue is associated with an increase in relative intensity of ESR components with magnetic anisotropy (fig. 2b, c), which can be attributed to the magnetic susceptibility anisotropy of ferritin/hemosiderin aggregates in tissues. The observed ESR shift on sample rotation in the spectrometer resonator is indicative of the local magnetic fields in aggregates of the order of at least several millitesla. One could speculate about possible effects of the magnetic fields due to ferritin/hemosiderin iron in pathological development, in particular, accounting for the catalysis of free radical oxidation in steady-state magnetic fields of 10-80 mT [39], or in the in vitro inhibition of phagocytic activity of immunocompetent cells placed in applied static magnetic fields of 25-150 mT [40].

The efficiency of iron chelators in the treatment of neuroblastoma, which is also characterized by increased ferritin and hemosiderin levels, has been observed both in cell culture and in patients [41, 42]. A set of iron chelators has already been shown to inhibit tumor cell growth and to have significant in vivo antineoplastic activity. It has been demonstrated that some iron chelators can penetrate the blood-brain barrier and that desferrioxamine is effective in diminishing central nervous system iron accumulation $[9,43]$. In this context it may be worthwhile to assess chelators for treatment of glial brain tumors.

\section{Conclusion}

In the present study we found that patients with malignant glial brain tumors exhibited hyperferremia in the blood, whereas experimental glial brain tumors in rats were marked by hypoferremia. Tumor tissue and adjacent peritumoral tissue were considerably enriched in stored and chelatable iron upon glial brain tumor formation in both the rat experimental model and in humans.

\section{Acknowledgments}

We are grateful to Alexandr Chochlov for excellent assistance with experimental animals and for patient sample collection throughout this study. 


\section{References}

1 Bird CL, Witte JS, Swendseid ME, Shikany JM, Hunt IF, Frankl HD, Lee ER, Longnecker MP, Haile RW: Plasma ferritin, iron intake, and the risk of colorectal polyps. Am J Epidemiol 1996;144:34-41.

-2 Herrinton LJ, Friedman GD, Baer D, Selby JV: Transferrin saturation and risk of cancer. Am J Epidemiol 1995;142:692-698.

- 3 Hsing AW, McLaughlin JK, Olsen JH, Mellemkjar L, Wacholder S, Fraumeni JF Jr: Cancer risk following primary hemochromatosis: A population-based cohort study in Denmark. Int J Cancer 1995;60:160-162.

-4 Nelson RL, Davis FG, Persky V, Becker E: Risk of neoplastic and other diseases among people with heterozygosity for hereditary hemochromatosis. Cancer 1995;76:875-879.

-5 Kovar J, Stunz LL, Stewart BC, Kriegerbeckova K, Ashman RF, Kemp JD: Direct evidence that iron deprivation induces apoptosis in murine lymphoma 38C13. Pathobiology 1997;65: 61-68.

6 Weinberg ED: Iron withholding: A defence against infection and neoplasia. Physiol Rev 1984;64:65-102.

7 Hughes NR: Serum transferrin and ceruloplasmin concentrations in patients with carcinoma, melanoma, sarcoma and cancers of haematopoietic tissues. Aust J Exp Biol Med Sci 1972;50:97-107.

-8 Okada S: Iron-induced tissue damage and cancer: The role of reactive oxygen species-free radicals. Pathol Int 1996;46:311-332.

-9 Brodie C, Siriwardana G, Lucas J, Schleicher R, Terada N, Szepesi A, Gelfand E, Seligman P: Neuroblastoma sensitivity to growth inhibition by deferrioxamine: Evidence for a block in G1 phase of the cell cycle. Cancer Res 1993; 53:3968-3975.

10 Link G, Saada A, Pinson A, Konijn AM, Hershko C: Mitochondrial respiratory enzymes are a major target of iron toxicity in rat heart cells. J Lab Clin Med 1998;131:466474.

11 Evans PH: Free radicals in brain metabolism and pathology. Br Med Bull 1993;49:577587.

12 Hazard JT, Drysdale JW: Ferritinaemia in cancer. Nature 1977;265:755-756.

13 Sandell EB: Colorimetric Determination of Traces of Metals. New York, Interscience, 1965, vol 3.

14 Dudchenko N, Mychaylyk O: Transferrin iron concentration and transferrin saturation in the whole blood. Biochemistry (Ukraine) 2000;72: 43-50.

-15 Kozlov AV, Yegorov DYu, Vladmirov YA, Azizova OA: Intracellular free iron in liver tissue and liver homogenate: Studies with electron-paramagnetic resonance on the formation of paramagnetic complexes with desferal and nitric oxide. Free Radic Biol Med 1992;13:916.
16 Dudchenko N, Mykhaylyk O: Quantification of chelatable iron in biological tissues using ESR technique on complexation with desferrioxamine B. Biochemistry (Ukraine) 1999;71: 122-127.

17 Mykhaylyk OM, Razumov ON, Dudchenko AK, Pankratov YuV, Dobrinsky EK, Sosnitsky VN, Bakai EA: Use of ESR, Mossbauer spectroscopy and SQUID-magnetometry for the characterization of magnetic nanoparticles on the base of metal iron and its implications in vivo; in Hafeli $U$, et al (eds): Scientific and Clinical Applications of Magnetic Carriers. New York, Plenum Press, 1997, pp 277-298.

18 Mykhaylyk OM, Dudchenko NA: Non-heme iron determination in biological samples on evidence derived from electron spin resonance data; in Collery $\mathrm{Ph}$ et al (eds): Metal Ions in Biology and Medicine. Paris, John Libbey Eurotext, 1998, vol 5, pp 3-7.

19 Mykhaylyk O, Török G, Dudchenko O, Stavinska O, Dudchenko N, Steinberg F: On the magnetic ordering of the iron storage proteins in tissues. J Magn Magn Mater 2004;272-276P3: 2422-2423.

20 Peisach J, Blumberg WE, Wittenberg BA, Wittenberg JB, Kampa L: Hemoglobin A: An electron paramagnetic resonance study of the effects of interchain contacts on the heme symmetry of high-spin and low-spin derivatives of ferric alpha chains. Proc Natl Acad Sci USA 1969;63:934-939.

21 Weil JA, Bolton JR, Wertz JE: Electron paramagnetic resonance - elementary theory and practical applications. New York, Wiley, 1994, $568 \mathrm{pp}$.

22 Bradbury MW: Transport of iron in the bloodbrain-cerebrospinal fluid system. J Neurochem 1997;69:443-454.

23 Suh YJ, Samuel D: Glycosylphosphatidylinositol-anchored ceruloplasmin is required for iron efflux from cells in the central nervous system. J Biol Chem 2003;278:27144-27148.

24 Lis A, Barone TA, Paradkar PN, Plunkett RJ, Roth JA: Expression and localization of different forms of DMT1 in normal and tumor astroglial cells. Brain Res Mol Brain Res 2004; 122:62-70.

25 Hann HW, Evans AE, Cohen IJ, Leitmeyer JE: Biologic differences between neuroblastoma stages IV-S and IV: Measurement of serum ferritin and E-rosette inhibition in 30 children. N Engl J Med 1981;305:425-429.

26 Kifle Y, Monnier J, Chesrown SE, Raizada MK, Nick HS: Regulation of the manganese superoxide dismutase and inducible nitric oxide synthase gene in rat neuronal and glial cells. J Neurochem 1996;66:2128-2135.

27 Matzner Y, Hershko C, Polliack A, Konijn AM, Izak G: Suppressive effect of ferritin on in vitro lymphocyte function. $\mathrm{Br} \mathrm{J}$ Haematol 1979;42:345-353.
28 Eisenstein RS, Garcia-Mayol D, Pettingell W, Munro HN: Regulation of ferritin and heme oxygenase synthesis in rat fibroblasts by different forms of iron. Proc Natl Acad Sci USA 1991;88:688-692.

-29 Schipper HM: Heme oxygenase-1: Transducer of pathological brain iron sequestration under oxidative stress. Ann NY Acad Sci 2004;1012: 84-93.

30 Watts RN, Ponka P, Richardson DR: Effects of nitrogen monoxide and carbon monoxide on molecular and cellular iron metabolism: Mirror-image effector molecules that target iron. Biochem J 2003;369:429-440.

- 31 Schlehofer B, Blettner M, Preston-Martin S, Niehoff D, Wahrendorf J, Arslan A, Ahlbom A, Choi WN, Giles GG, Howe GR, Little J, Menegoz F, Ryan P: Role of medical history in brain tumour development: Results from the international adult brain tumour study. Int $\mathrm{J}$ Cancer 1999;82:155-160.

32 Lote K, Stenwig AE, Skullerud K, Hirschberg $\mathrm{H}$ : Prevalence and prognostic significance of epilepsy in patients with gliomas. Eur J Cancer 1998;34:98-102.

33 Penfield W, Erickson TC, Tarlov I: Relation of intracranial tumors and symptomatic epilepsy. Arch Neurol Psychiatry 1940;44:300-315.

34 Willmore LJ: Post-traumatic epilepsy: Cellular mechanisms and implications for treatment. Epilepsia 1990;31(suppl 3):S67-S73.

- 35 Willmore LJ, Sypert GW, Munson JB, Hurd RW: Chronic focal epileptiform discharges induced by injection of iron into rat and cat cortex. Science 1978;200:1501-1503.

- 36 Willmore LJ, Rubin JJ: Antiperoxidant pretreatment and iron-induced epileptiform discharges in the rat: EEG and histopathologic studies. Neurology 1981;31:63-69.

37 Wen WN: Methemoglobin contributes to the growth of human tumor cells. Life Sci 2002;70: 907-916.

38 Kennett EC, Kuchel PW: Redox reactions and electron transfer across the red cell membrane. IUBMB Life 2003;55:375-385.

- 39 Lalo UV, Pankratov YV, Mykhaylyk OM: Steady magnetic fields effect on lipid peroxidation kinetics. Redox Rep 1994;1:71-75.

40 Flipo D, Fournier M, Benquet C, Roux P, Le Boulaire C, Pinsky C, LaBella FS, Krzystyniak $\mathrm{K}$ : Increased apoptosis, changes in intracellular $\mathrm{Ca}^{2+}$, and functional alterations in lymphocytes and macrophages after in vitro exposure to static magnetic field. J Toxicol Environ Health 1998;54:63-76.

41 Hann HW, Levy HM, Evans AE: Serum ferritin as a guide to therapy in neuroblastoma. Cancer Res 1980;40:1411-1413.

42 Iancu TC, Shiloh H, Kedar A: Neuroblastomas contain iron-rich ferritin. Cancer 1988;61: 2497-2502.

43 Estrov Z, Tawa A, Wang XH, Dube ID, Sulh H, Cohen A, Gelfand EW, Freedman MH: In vitro and in vivo effects of deferoxamine in neonatal acute leukemia. Blood 1987;69:757761. 